\title{
Dual-Frequency Approach to Assess Surface Hardened Layer Using NDE Technology
}

\section{Mehrdad Kashefi \& Saeed Kahrobaee}

Journal of Materials Engineering and Performance

ISSN 1059-9495

Volume 22

Number 4

J. of Materi Eng and Perform (2013) 22:1108-1112

DOI 10.1007/s11665-012-0369-y

\section{JOURNAL OF MATERIALS ENGINEERING AND PERFORMANCE ${ }^{\circledR}$ \\ DESIGN • PROCESS • CHARACTERIZATION • EVALUATION}

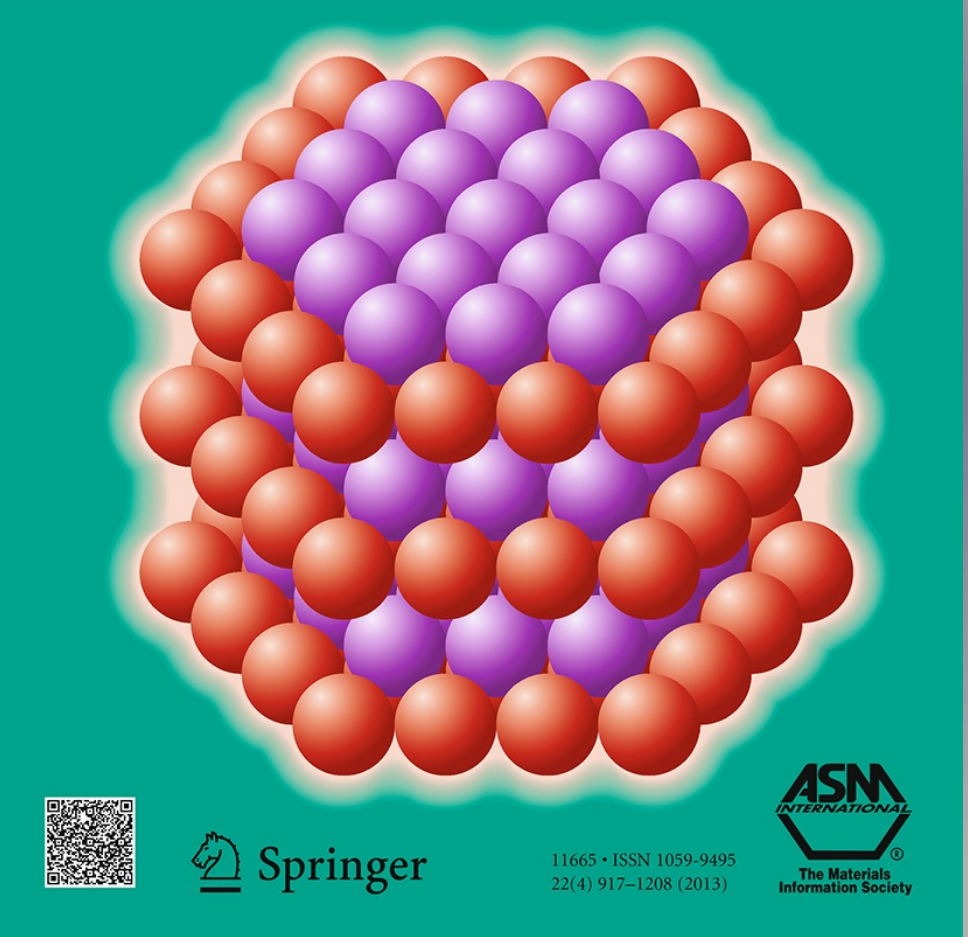


Your article is protected by copyright and all rights are held exclusively by ASM International. This e-offprint is for personal use only and shall not be self-archived in electronic repositories. If you wish to selfarchive your work, please use the accepted author's version for posting to your own website or your institution's repository. You may further deposit the accepted author's version on a funder's repository at a funder's request, provided it is not made publicly available until 12 months after publication. 


\title{
Dual-Frequency Approach to Assess Surface Hardened Layer Using NDE Technology
}

\author{
Mehrdad Kashefi and Saeed Kahrobaee
}

\author{
(Submitted March 3, 2012; in revised form June 21, 2012; published online September 15, 2012)
}

\begin{abstract}
Inspection and quality control of induction hardened parts require a good understanding of the depth of the hardened layer. Traditional destructive methods to determine the case depth are considered to be costly and time-consuming. The eddy current (EC) technique is sensitive to micro-structural changes; hence, it can be used to determine the case depth based on the differences in magnetic properties between the hardened layer and the core of the specimen. In this study, identical rods of AISI 1045 mild carbon steel were surface hardened using induction hardening technique. In order to investigate the applicability of the EC technique, the relations between obtained effective and total case depths and the EC outputs (induced voltage, normalized impedance, phase angle, and their harmonic characteristics) were studied. The results show a maximum of correlation coefficient of $94 \%$ in determining case depths by EC technique.
\end{abstract}

Keywords carbon steel, heat treating, nondestructive testing, surface engineering

\section{Introduction}

Induction hardening is a process where a metallic part is hardened by means of induction heating and subsequent quenching in aqueous media. This hardening technique combines traditional heat treatment principles with a modern surface heating method utilizing induced current. From industrial point of view, the determination of case depths through designing integrated control systems is so valuable. This, in turn, results in saving time and energy as well as providing $100 \%$ inspection in mass production lines. The standard methods for determining case depth are metallographic examination and hardness profile plotting which are done by random sampling and sectioning the heat treated parts. These methods are time-consuming, costly, and cannot be used as real-time methods. In addition, only a fraction of the production volume can be tested. From the industrial point of view, ideally, the entire production volume should be examined by a fast and economic method. These requirements present an opportunity for applying nondestructive techniques. Considering the advantages of nondestructive methods in industrial quality control, in the recent years, many researchers have focused on nondestructive evaluation (NDE) of the mechanical and physical properties of materials as an alternative to destructive methods. Among different NDE methods, eddy current (EC) technique has gained advantages such as high sensitivity to chemical

Mehrdad Kashefi, Department of Materials Science and Metallurgical Engineering, Engineering Faculty, Ferdowsi University of Mashhad, Mashhad, Iran; and Saeed Kahrobaee, Department of Materials Science and Metallurgical Engineering, Sadjad Institute of Higher Education, Mashhad, Iran. Contact e-mails: saeed_kahrobaee@yahoo.com and m-kashefi@um.ac.ir. composition, microstructure, mechanical properties, and residual stress, thus making it a reliable alternative to conventional destructive methods.

Over the past decade, the evaluation of the microstructural changes using EC nondestructive method has been carried out through several studies. For instance, the percentage of pearlite in plain carbon steels and ductile cast irons (Ref 1-3), surface characterization of carburized and decarburized steels (Ref 4, 5), and the thermal treatment effects (effects of prolonged aging) on maraging steel (Ref 6) have been evaluated using EC technique. Studies mentioned above indicate that EC technique is suitable for the characterization of microstructural changes, indirectly.

Recently, several studies have been conducted to investigate electrical and magnetic properties of induction hardened steels. Studying magnetic hysteresis loss values and Magnetic Barkhausen Noise effects (Ref 7,8) as well as electrical conductivity and magnetic permeability (Ref 9) showed that there are differences between magnetic properties of the hardened layer and the core of the sample. Therefore, there is a potential for EC technique to detect these microstructural changes in the surface of induction hardened parts.

In this study, to penetrate the induced EC into each specified depth which corresponds to the effective and total case depth (TCD), two optimum operating frequencies were calculated and applied. Also, various forms of presenting test results of EC method (relations between measurable and calculable outputs and case depth, impedance plane, and the movement of the location of impedance point due to the surface micro-structural changes and harmonic analysis of EC signals) have been applied. Therefore, a novel approach and comprehensive study are developed to increase the accuracy of measurements.

\section{Experimental Method}

Nine AISI 1045 steel rods $30 \mathrm{~mm}$ in diameter and $150 \mathrm{~mm}$ in length were prepared for the induction hardening process. The steel composition was as follows: $0.44 \% \mathrm{C}-0.57 \%$ 
Mn- $0.25 \%$ Si- $0.03 \%$ S- $0.004 \%$ P. For all samples, the frequency and the power of induction hardening system were fixed at $30 \mathrm{kHz}$ and $50 \mathrm{~kW}$, respectively. By changing the speed of the sample in the course of passing through the induction coil (12 to $6.5 \mathrm{~mm} / \mathrm{s}$ ), different case depths were produced. In the case of samples with the same chemical composition, EC outputs are affected by two important factors: microstructural changes and residual stress (Ref 10). Thus, to eliminate residual stress, all samples were tempered at a temperature of $250{ }^{\circ} \mathrm{C}$ for $2 \mathrm{~h}$. The micro-hardness profiles were plotted using Vickers indenter on a Bohler micro-hardness tester. For each sample, five different hardness profiles were plotted up to $6 \mathrm{~mm}$, using a $9.8 \mathrm{~N}$ load.

Finally, the EC tests were carried out on the cylindrical samples. An encircling coil of $30.5 \mathrm{~mm}$ internal diameter and $120 \mathrm{~mm}$ length was used whose numbers of turns for the primary (excitation) and secondary (detection) coils were 500 and 650 , respectively. A schematic diagram of the employed EC system is shown in Fig. 1. The EC test was carried out at a temperature of $27^{\circ} \mathrm{C}$ with the filling factor of 0.98 . A sinusoidal current on the frequency range of $10-100 \mathrm{~Hz}$ (in $5 \mathrm{~Hz}$ steps) was applied to the coil on all samples. Induced voltages and input currents were measured and the impedance of the coil and the phase angle were calculated. Harmonic analysis (Fast Fourier Transformation) was also used to establish relations between the received waves from EC voltage and case depths.

\section{Results and Discussion}

\subsection{Hardness Measurement to Determine Case Depth}

Figure 2 indicates the optical microstructural image in a cross section of an induction hardened sample. As it can be seen, the hardened zone with a martensitic structure close to the surface is darker than ferrite-pearlitic structure of the core, which is not affected by heat treatment.

According to the International Standard ISO 3754, effective case depth (ECD) is defined as: "The distance between the surface of the product and the layer where the Vickers Hardness (HV) under a load of $9.8 \mathrm{~N} \mathrm{(1} \mathrm{kgf)} \mathrm{is} \mathrm{equal} \mathrm{to} \mathrm{the} \mathrm{value}$

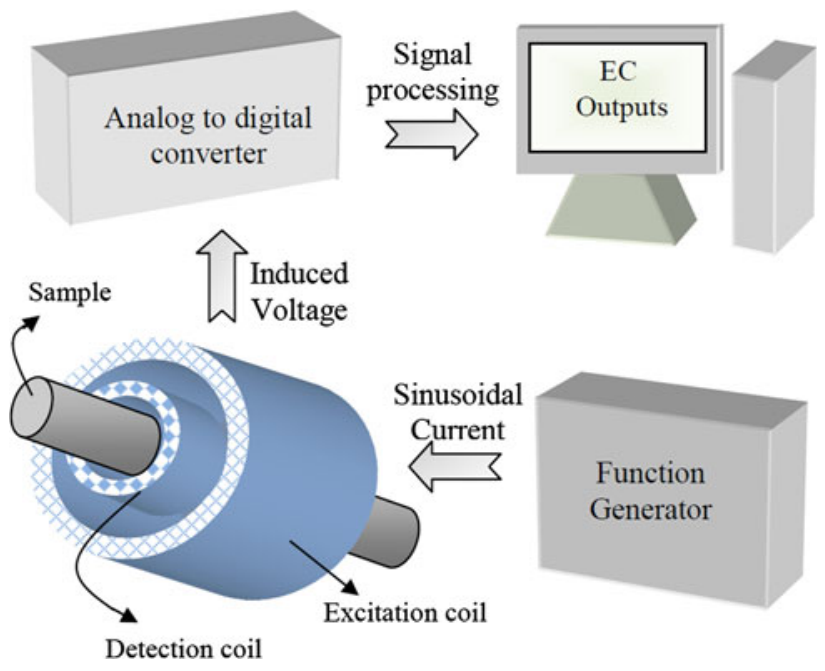

Fig. 1 Schematic diagram of eddy current testing system specified by the term "hardness limit'." It is a function of the minimum surface hardness required for the part, given by Eq 1

Hardness limit $(\mathrm{HV})=0.8 \times$ minimum surface hardness.

(Eq 1)

Since, in the present investigation, the minimum surface hardness of all samples is $625 \mathrm{HV}$, the ECD is considered as the perpendicular distance between the surface and the layer having a hardness of $500 \mathrm{HV}$. On the other hand, the TCD is considered the distance from the surface to a limit beyond which the hardness remains constant. The measured effective and TCD values are shown in Table 1 .

\subsection{Investigating the EC responses}

In micro-structural characterization of the surface by EC method, the determination of the optimum frequency is considered as the first step. In this article, optimum frequencies for ECD and TCD have been chosen by two methods: (1) applying regression analysis between the case depths and the EC outputs (Ref 10) and (2) using electromagnetic skin depth equation (Ref $5,11,12)$.

In the regression analysis, relations between EC outputs and ECD as well as TCD were investigated in the range of 10$100 \mathrm{~Hz}$ (in $5 \mathrm{~Hz}$ steps). Then, correlation coefficients $\left(R^{2}\right)$ of the relations were calculated on each frequency. The results of the frequency sweep are presented in Fig. 3. The maximum value of $R^{2}$ was obtained at $50 \mathrm{~Hz}$ for ECD and $25 \mathrm{~Hz}$ for TCD. Thus, these frequencies were chosen as the optimum ones.

The second method can be explained using the well-known equation for electromagnetic skin depth of a homogeneous magnetic field parallel to surface as an approximation. The depth at which the induced magnetic field decreases to $1 / e$ of the incident value is called skin depth $(\delta)$, which is given by Eq 2

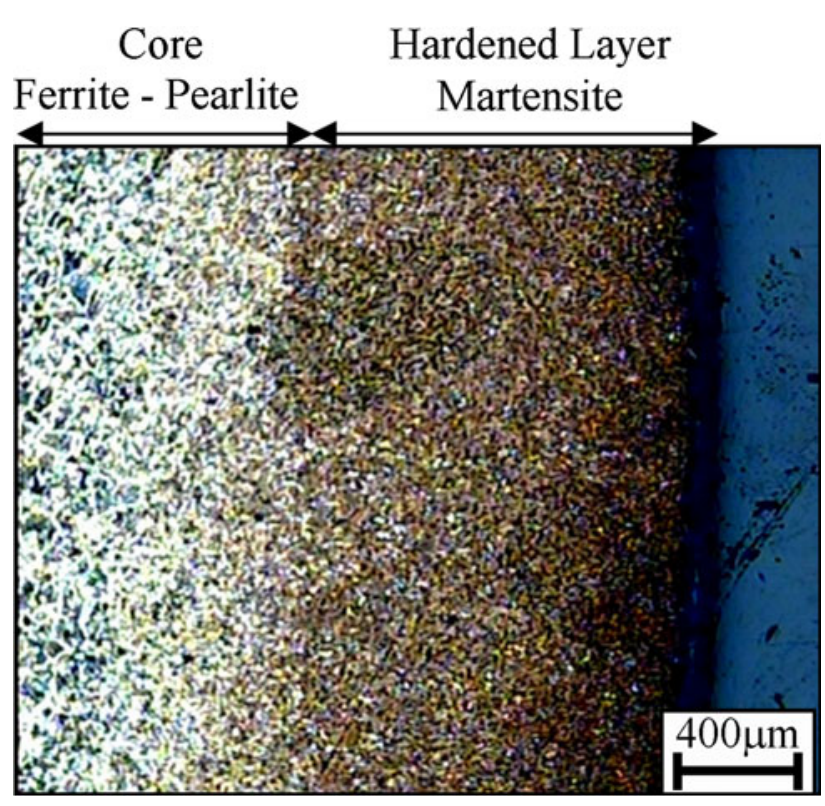

Fig. 2 The microstructure of an induction hardened sample created with the specimen passing through the induction heating coil at a speed of $12 \mathrm{~mm} / \mathrm{s}$ 
Table 1 Estimated ECD and TCD from hardness measurements

\begin{tabular}{|c|c|c|c|c|c|c|c|c|c|c|}
\hline Sample & $\mathbf{A}$ & B & $\mathbf{C}$ & $\mathbf{D}$ & $\mathbf{E}$ & $\mathbf{F}$ & $\mathbf{G}$ & $\mathbf{H}$ & I & $\mathbf{J}$ \\
\hline The speed of the sample in the course of passing the induction coil, $\mathrm{mm} / \mathrm{s}$ & 0.0 & 12.0 & 11.0 & 10.5 & 10.0 & 9.0 & 8.0 & 7.5 & 7.0 & 6.5 \\
\hline $\mathrm{ECD}, \mathrm{mm}$ & 0.0 & 0.7 & 1.9 & 2.0 & 2.2 & 2.3 & 3.2 & 3.3 & 3.5 & 4.1 \\
\hline $\mathrm{TCD}, \mathrm{mm}$ & 0.0 & 1.6 & 2.2 & 2.4 & 2.6 & 3.2 & 4.0 & 4.2 & 4.6 & 5.6 \\
\hline
\end{tabular}

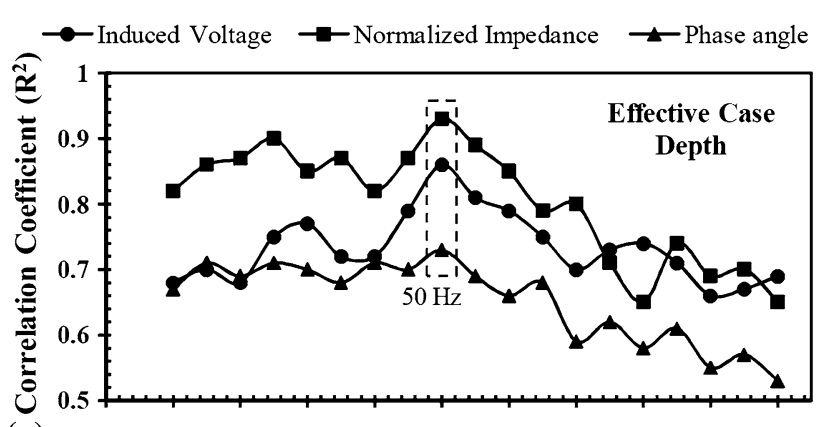

(a)

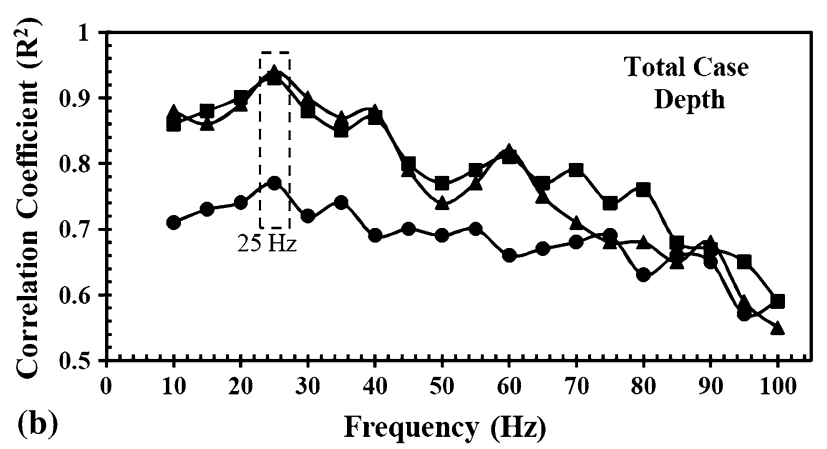

Fig. 3 Correlation coefficients as a function of applied frequency for (a) effective case depth and (b) total case depth

$\delta=1 / \sqrt{\pi f \mu_{0} \mu_{\mathrm{r}} \sigma}$

where $f$ is frequency in $\mathrm{Hz}, \sigma$ is electrical conductivity in $\Omega^{-1} \cdot \mathrm{m}^{-1}, \mu_{\mathrm{r}}$ is relative magnetic permeability and $\mu_{0}$ is the permeability of vacuum $\left(4 \pi \times 10^{-7} \mathrm{H} / \mathrm{m}\right)$.

As presented in Table 1, the maximum values of ECD and TCD were measured as 4.1 and $5.6 \mathrm{~mm}$, respectively. In order to detect changes in magnetic properties due to the presence of martensitic microstructure in the hardened layer, the calculatedinduced EC penetration depth should be equal or greater than these values.

Considering the fact that relative permeability and conductivity of the hardened layer have the values 75 (Ref 9) and $0.41 \times 10^{7} \Omega^{-1} \cdot \mathrm{m}^{-1}$, the skin depths achieved were 4.1 and $5.6 \mathrm{~mm}$ at 52 and $25 \mathrm{~Hz}$, respectively. These values for skin depths mean that induced currents of sensor penetrate into the maximum depth measured for ECD and TCD. Consequently, the induced EC can be used for all other investigated samples (whose ECD and TCD values are smaller than 4.1 and $5.6 \mathrm{~mm}$ ) to monitor micro-structural changes. Therefore, it can be concluded from both proposed methods that 50 and $25 \mathrm{~Hz}$ are the optimum frequencies for the evaluation of the effective and TCDs, respectively.

Figure 4 shows the relationships between induced voltage and ECD/TCD at 50 and $25 \mathrm{~Hz}$, respectively. As seen in the
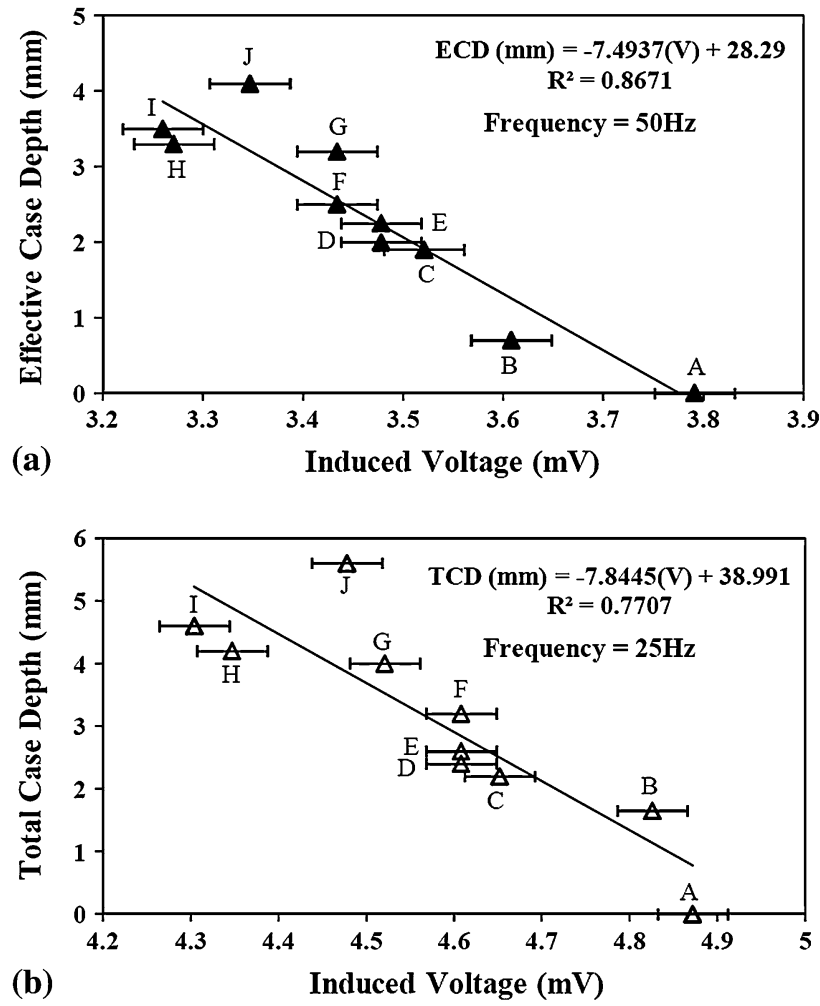

Fig. 4 Relations between the primary $\left(V_{x}\right)$ and secondary voltages $\left(V_{y}\right)$ with (a) ECD at $50 \mathrm{~Hz}$ and (b) TCD at $25 \mathrm{~Hz}$

figure, the correlation coefficients for ECD and TCD were obtained as 0.86 and 0.77 respectively.

To find a better relationship, relations between the calculated EC outputs (normalized impedance $\left(Z / Z_{0}\right)$ and phase angle $(\varphi)$ ) and ECT/TCD were studied. The details of the calculations for these outputs can be found elsewhere (Ref 3-5, 13). The relationship between the case depths and the calculated parameters is shown in Fig. 5. As it can be seen, in order to determine ECD, the best value for correlation coefficient $\left(R^{2}=0.93\right)$ is obtained through normalized impedance. For TCD, high correlation coefficients are obtained through both the normalized impedance $\left(R^{2}=0.93\right)$ and the phase angle $\left(R^{2}=0.94\right)$.

As a result of martensitic transformation in the hardened layer, there is high density of dislocations which caused by shear mechanism. This high dislocation density, plus high distortion (due to the interstitial atoms embedded in the structure of martensite) cause the pinning of magnetic domain walls which, in turn, reduces the mobility of magnetic domain walls in comparison with ferrite-pearlite microstructure with lower dislocation density (Ref 8,9 ). Thus, a higher magnetic field intensity $(H)$ is required to overcome the obstacles to aligning the domains and, therefore, more coercivity is needed. 

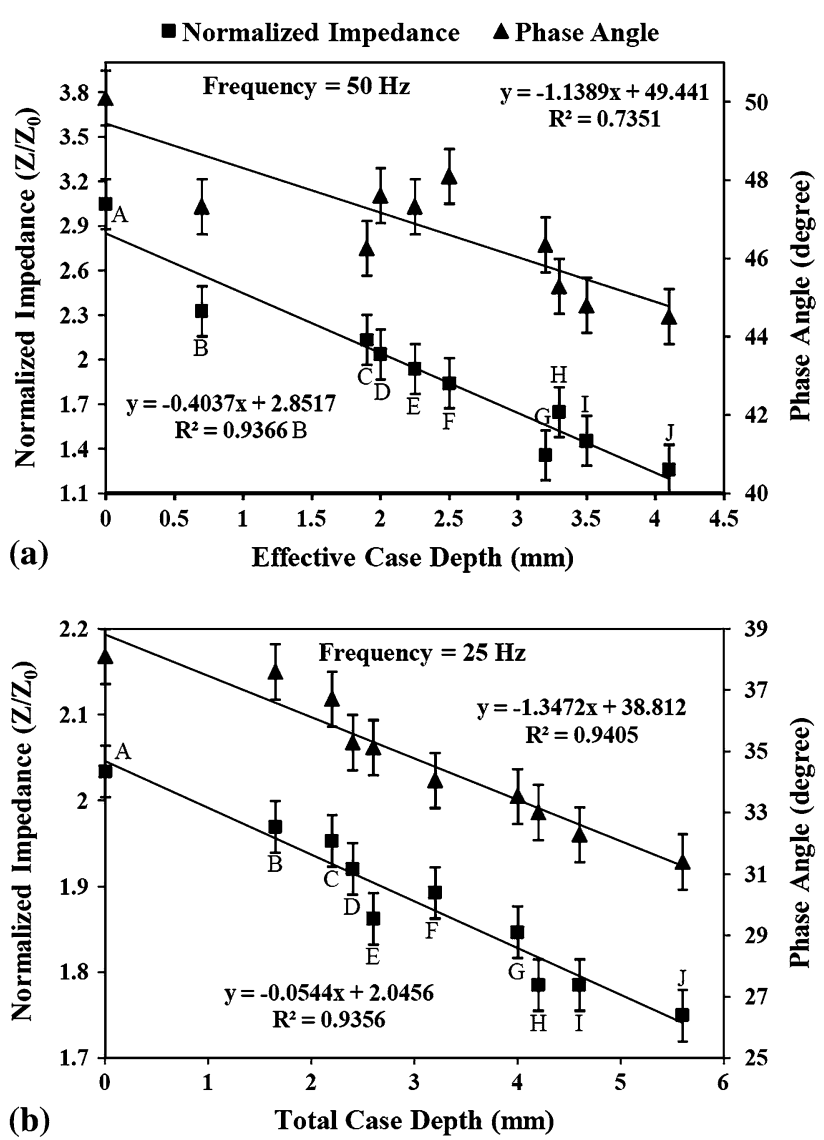

Fig. 5 Relations between normalized impedance $\left(Z / Z_{0}\right)$ and phase angle $(\varphi)$ with a) ECD at $50 \mathrm{~Hz}$ and b) TCD at $25 \mathrm{~Hz}$

As a result, by increasing the case depth (martensite microstructure), coercivity and hysteresis loss increase but magnetic permeability $(\mu)$ decreases. Considering $\mathrm{Eq} 3$, it can be concluded that a decrease in $\mu$ results in a decrease in selfinduction coefficient $(L)$

$L=\frac{\mu N^{2} A}{l}$,

where $\mu$ is the magnetic permeability, $N$ is the number of turns round the coil, $A$ is the cross-sectional area, and $l$ is the coil length.

According to Eq 4, by decreasing magnetic permeability $(\mu)$, reactance $\left(X_{L}\right)$ decreases. Since in ferromagnetic alloys (such as steel) the effect of permeability or reactance is stronger than the effect of resistance $(R)$, impedance $(Z)$ also decreases Eq 5

$X_{L}=2 \pi f L$

$Z=\sqrt{X_{L}^{2}+R^{2}}=V / I$.

In brief, the impedance decreases when the hardened depth increases. This is considered as the main reason for decreasing the output voltage of EC by increasing hardened depth (Fig. 4, 5). As a result, the differences in magnetic properties of martensite and ferrite-pearlite microstructures make EC technique a suitable approach to characterizing the case depth.

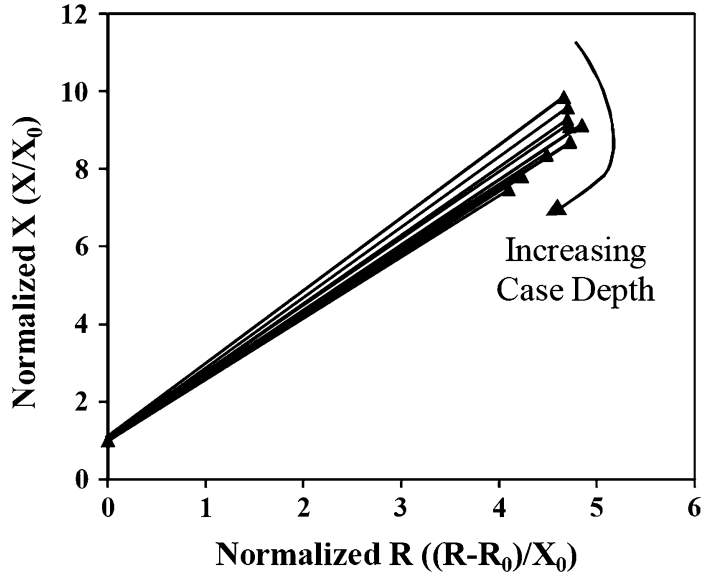

Fig. 6 Impedance plane and effect of case depth on location of impedance point

To investigate different aspects of hardened depth effects on EC responses, impedance plane has been developed and analyzed for all samples. Theoretical calculations for the impedance plane can be found elsewhere $(\operatorname{Ref} 4,5,14)$. The results of the calculations are presented in Fig. 6. The figure demonstrates the effect of TCD on the location of impedance point, which in turn, can be used to calculate phase angle $(\varphi)$. Figure 6 also shows a reduction in phase angle when the hardened depth of the samples increases.

Harmonic analysis (using Fast Fourier Transformation) has been introduced in the last few years as an industrial tool for materials characterization of ferromagnetic materials. The technique has been proven to be a reliable and cost effective alternative to traditional destructive quality control methods (Ref 5, 15).

To study its application in determining the case depth, harmonic analysis was applied to the EC obtained signals (voltage) at the frequency of $25 \mathrm{~Hz}$. Real (Re) and imaginary (Im) parts of each harmonic as well as their modulus (П) Eq 6 were used to establish the relationship between different values of harmonics modulus and TCD values, separately

$\Pi=\sqrt{(\operatorname{Re})^{2}+}(\operatorname{Im})^{2}$.

In this study, only harmonics 3,5 , and 7 are used to characterize the case depth. Figure 7(a) to (c) shows the imaginary and the real part of the three harmonics as a function of case depth. It is worth noting that the amplitude of the signal for the imaginary part and the harmonics modulus increases, while the real part of the harmonic decreases to the extent of case depth (Fig. 7). As it is shown, high correlation coefficients have been obtained. Comparing the results of the harmonic analysis with the EC outputs, it is concluded that the imaginary part and the harmonics modulus can be properly used as alternatives to phase angle and normalized impedance in determining TCD.

Last but not least, one should bear in mind that one of the major advantages of the proposed technique is its fast and reliable response which can be used in quality control in industrial mass production lines. After the calibration of the EC system for reference samples, determining case depth values for unknown ones (with the same chemical composition) can be done in a few seconds. 


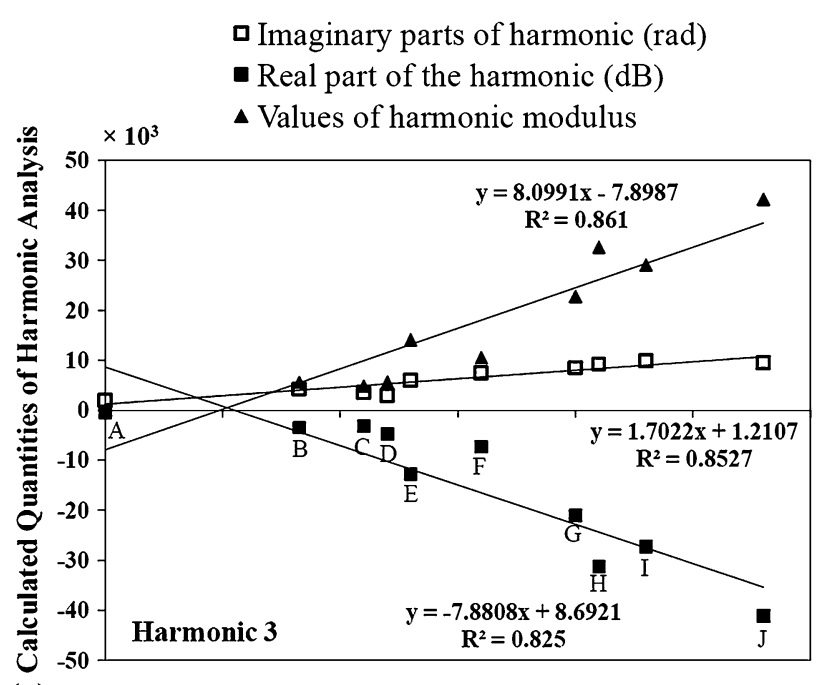

(a)

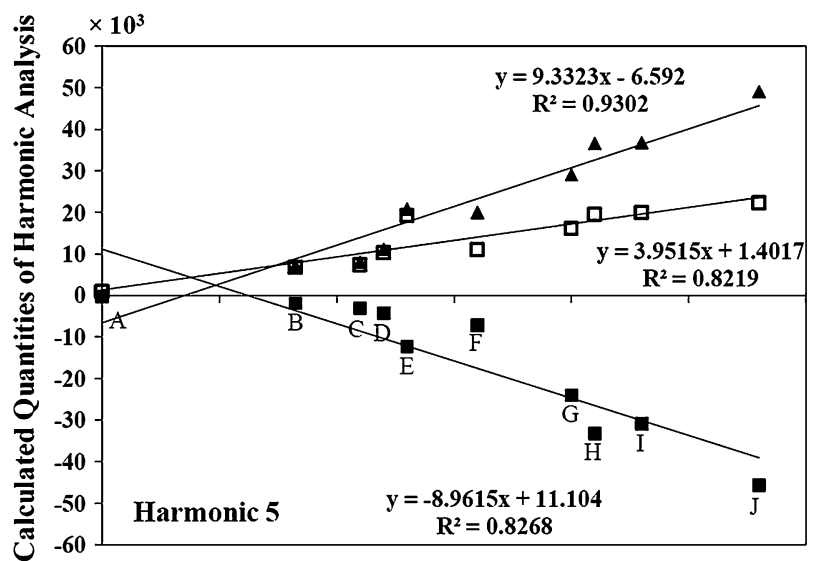

(b)

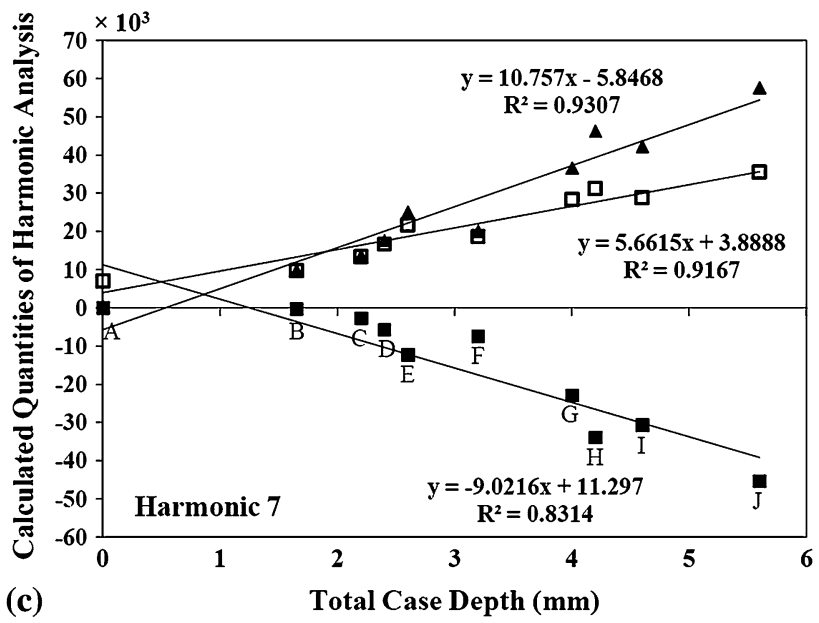

Fig. 7 Relations between total case depth and the 3rd (a), 5th (b), and 7th (c) harmonics of the output secondary coil signal at $25 \mathrm{~Hz}$

\section{Conclusions}

In this study, EC method was used to determine the effective and TCDs in induction hardened AISI 1045 steels. Considering the importance of determining optimum frequency in the nondestructive surface characterization, two methods (electromagnetic skin depth equation and regression analysis) were employed and frequencies of 50 and $25 \mathrm{~Hz}$ were obtained as the optimum ones. Besides, outputs of normalized impedance, phase angle, and harmonics modulus were considered as the optimum ones due to the high correlation coefficients (0.930.94) of investigated correlations between EC outputs and ECD/TCD values. The results showed that the case depth measurement accuracy could be improved by the determination of the optimum frequencies and outputs. The proposed technique provides an effective, fast, and reliable quality control of the industrial parts.

\section{References}

1. S. Konoplyuk, Estimation of Pearlite Fraction in Ductile Cast Irons by Eddy Current Method, NDT\&E Int., 2010, 43, p 360-364

2. S.H. Khan, A. Farhad, A. Nusair Khan, and M.A. Iqbal, Pearlite Determination in Plain Carbon Steel by Eddy Current Method, J. Mater. Process. Technol., 2008, 200, p 316-318

3. M. Kashefi, S. Kahrobaee, and M.H. Nateq, On the Relationship of Magnetic Response to Microstructure in Cast Iron and Steel Parts, J. Mater. Eng. Perform., 2012, 21, p 1520-1525

4. M. Sheikh Amiri and M. Kashefi, Application of Eddy Current Nondestructive Method for Determination of Surface Carbon Content in Carburized Steels, NDT\&E Int., 2009, 42, p 618-621

5. S. Kahrobaee, M. Kashefi, and A. Saheb Alam, Magnetic NDT Technology for Characterization of Decarburizing Depth, Surf. Coat. Technol., 2011, 205, p 4083-4088

6. S.H. Khan, A. Nusair Khan, F. Ali, M.A. Iqbal, and H.K. Shukaib, Study of Precipitation Behavior at Moderate Temperatures in 350 Maraging Steel by Eddy Current Method, J. Alloys Compd., 2009, 474, p 254-256

7. C. Zhang, N. Bowler, and C. Lo, Magnetic Characterization of Surface-Hardened Steel, J. Magn. Magn. Mater, 2009, 321, p 3878 3887

8. C.C.H. Lo, E.R. Kinser, Y. Melikhov, and D.C. Jiles, Review of Progress in Quantitative Nondestructive Evaluation 25B, AIP Conference Proceedings, Vol. 820, D.O. Thompson, D.E. Chimenti, Ed., 2006, p 1253-1260

9. M. Johnson, C. Lo, S. Hentscher, and E. Kinser, Analysis of Conductivity and Permeability Profiles in Hardened Steel, Electromagnetic Nondestructive Evaluation (IX), L. Udpa and N. Bowler, Ed., Amsterdam, IOS, 2005, p 135-142

10. D.J. Hagemaier, Fundamentals of Eddy Current Testing, ASNT, Columbus, 1990

11. S. Kahrobaee and M. Kashefi, Hardness Profile Plotting Using Multifrequency Multi-output Electromagnetic Sensor, NDT\&E Int., 2011, 44, p 335-338

12. X.J. Hao, W. Yin, M. Strangwood, A.J. Peyton, P.F. Morris, and C.L. Davis, Off-line Measuremnt of Decarburization of Steels Using a Multifrequency Electromagnetic Sensor, Scripta Mater, 2008, 58, p $1033-1036$

13. P.J. Shull, Nondestructive Evaluation: Theory, Techniques and Applications (Chapter 5), Marcel Dekker, Inc., New York, 2002

14. M. Sheikh Amiri and M. Kashefi, Investigation of Variables Affecting Impedance Plane in Eddy Current Testing of Carburized Steels, J. Mater. Eng. Perform., 2011, 20, p 476-480

15. H. Klümper-Westkamp, P. Mayr, W. Reimche, K.L. Feiste, M. Bernhard, and F.W. Bach, International Symposium (NDT-CE 2003), Nondestructive Testing in Civil Engineering, Berlin, Germany, 2003, p 364-372 